Pakistan Journal of Nutrition 11 (10): 900-905, 2012

ISSN 1680-5194

(C) Asian Network for Scientific Information, 2012

\title{
The Role of Prelacteal Feeding in Infant Methemoglobinemia Risk: Case Study in the Upper East Region of Ghana
}

\author{
Kubuga Clement Kubreziga \\ University for Development Studies, Community Nutrition Department, \\ Box TL 1883, Tamale, Ghana, West Africa
}

\begin{abstract}
Exposure to high nitrate concentration and prelacteal feeding increase the risk of infant methemoglobinemia. This research was therefore carried out to test for the presence and concentration of nitrates in drinking water for households in upper east region where prelacteal feeding is common as compared to other regions in Ghana and to determine the risk of exposure to methemoglobinemia through unregulated sources of drinking water. An experimental study was carried out: Seven districts, twenty Communities and twenty eight unregulated sources of drinking water (nineteen wells and nine boreholes) were randomly selected. Key informant interviews were carried out in various selected communities to ascertain the number of existing and functional water sources. Nitrate-Nitrogen was determined using the hydrazine reduction method. $43 \%$ of these water sources had nitrate levels above accepted limits indicating that nearly three (3) out of seven (7) unregulated water sources expose the consumers to high nitrate concentration (beyond $10 \mathrm{mg} / \mathrm{L}$ ) which is highly unacceptable. $57 \%$ of them were however considered to be safe for consumption. Implying that nearly four (4) out of seven (7) unregulated water sources could be said to be safe for consumption. The margin between consuming safe and unsafe water from unregulated water sources in the region was therefore observed to be very slim. The risk of being exposed to methemoglobinemia was found to be 0.08 ; meaning about one (1) out of every twelve (12) children stands the risk of being exposed to methemoglobinemia when using unregulated water sources. Comparing wells and boreholes, the risk of wells was found to be 0.08 which is the same as the combined risk for all unregulated water sources. It can therefore be said that well water accounts largely for the risk of exposure to methemoglobinemia in the region. The risk from boreholes stood at 0.06 . The difference in the two sources was attributed to boreholes being covered and sunk deeper than most wells.
\end{abstract}

Key words: Prelacteal feeding, methemoglobinemia, nitrates, upper east region-Ghana

\section{INTRODUCTION}

Almost all mothers in Ghana breast-feed their children however exclusive breast feeding has short duration; 84 percent of children under 2 months of age are exclusively breast-fed while the remaining 16 percent are not. By age 4-5 months, more than half of them (51\%) are not exclusively breast-fed while only 49 percent are still being exclusively breast-fed. Further more research indicate that more than one in five babies ever breast-fed received a prelacteal feed (GDHS, 2008). GDHS went further to say that the practice of giving the baby a prelacteal feed is more common in the Upper East, Ashanti, Western and Central regions of Ghana, where more than one in five children $(18 \%)$ received a prelacteal feed. $22 \%$ of children in households in the middle wealth quintile received prelacteal feed.

Children in rural areas are breast-fed somewhat longer than children in urban areas (21 months, compared with 19 months). It is however worth noting that breast feeding does not necessarily mean exclusive breast feeding. The median duration of any breast feeding decreases with increasing level of education and increasing wealth quintile.

Ahmed et al. (1996) has it that prelacteal feeding is largely influence by some key factors such as believes / social customs, maternal health status, mode of delivery - caesarian vs vaginal, term vs preterm. As to the constitution of the feed, it is largely water or embodies the use of water (GDHS, 2008) except in foods such as honey (Ahmed, 1996) but sometimes these foods are equally diluted with water. This thus suggests that infants under going prelacteal feeding stand at a higher risk of methemoglobinemia once the water sources have unacceptable levels of nitrates.

Problem statement: Unlike regulated public water source (pipe water), unregulated water sources (wells and boreholes) usually do not have their nitrate concentration checked or regulated. Nitrates amounts or concentrations in these water sources are often 
unknown. High amounts of nitrates in drinking water is however a global concern since unacceptable amountsof nitrates could lead to major health problems such as cancer, birth defects and methemoglobinemia which is peculiar to children.

Justification: Exposure to high nitrate concentration in water and prelacteal feeds increase the risk of infant methemoglobinemia. In Ghana, prelacteal feeds are largely water base or embody the use of water except in foods such as honey however honey is sometimes diluted with water. This therefore compounds the problem further where both water and prelacteal feed are highly contaminated. In Upper East Region, prelacteal feeding is common as compared to other regions in Ghana. This possibly predisposition children in the region to all the ills associated to prelacteal feeding. The risk of exposure to high nitrate concentrations is unclear, the need to determine nitrate concentrations in water use for prelacteal feeds and the risk of exposure to unacceptable nitrate amounts and or methemoglobinemia in the region is therefore very vital. Objectives:

C To test for the presence of nitrates in drinking water for households in upper east region where prelacteal feeding is common as compared to other regions in Ghana

C To compare the results gathered to existing standards for allowable amounts of nitrates in drinking water by the World Health Organization

C To determine the risk of exposure to methemoglobinemia through drinking water

\section{MATERIALS AND METHODS}

Design: An experimental method of research was performed to assess the presence or absence of nitrates in selected sources of drinking water; and the concentration of nitrates in each water source if present.

Target water sources: The target water sources were basically unregulated water sources (wells and boreholes). Regulated water sources includes routine checks for nitrates levels, besides, about seventy percent of the total population in the region rely on these water sources.

Selection of districts, communities and water sources: Districts were randomly selected. Communities and their sources of drinking water (wells and boreholes) were equally randomly selected from the Upper East Region of Ghana. Seven districts, twenty Communities and twenty eight sources of drinking water (nineteen wells and nine boreholes). The numbers of districts, communities and wells selected were subject to financial constrains.
Key informant interviews: Assembly men, women groups' leaders and village committee members were asked to list the sources of drinking water in their various communities (sampled communities). They were equally asked to specify whether the wells were open or closed Selection of water sources was then done randomly using this list.

Analysis: Water samples were collected from wells and bore holes using cleaned and sterilized bottles with lids. Nitrate-Nitrogen was determined using the hydrazine reduction method (Mullin and Riley, 1955: Kamphake et al. 1967)

\section{Literature review}

Pathophysiology of methemoglobinemia: The possible hazard associated with ingestion of high levels of nitrates in food or water is the inaccessibility of oxygen by body cells: When nitrate is ingested it is converted to nitrite. The Nitrite present reacts with hemoglobin (the proteins responsible for transporting oxygen in the body), converting it to methemoglobin, a form that is incapable of carrying oxygen. The affected individual therefore suffers from oxygen deprivation. In other words, the resulting compound (methemoglobin) is incapable of binding with molecular oxygen and produces a leftward shift in the oxygen-dissociation curve which results in hypoxymia. (EWG, 2012; Greer and Shannon 2005).

It is however worth noting that methemoglobinemia could be caused by so many factors and not just by nitrates only (McKnight et al ., 1999; Phillips, 1971).

Infants below four months of age are most susceptible to methemoglobinemia because their stomach is relatively non-acidic, meaning that compared to adults more nitrate is converted to nitrite in the infant stomach and because infant or fetal hemoglobin reacts to form methemoglobin easier than adult hemoglobin. (EWG, 2012).

Methemoglobin could be converted back to hemoglobin by methemoglobin reductases, an enzyme found in red blood cells. About ninety nine percent of this reduction is often accounted for by cytochrome $-b_{5}$ methemoglobin reductase; this activity is however reduced by half in infants as compared to adults (Smith, 1991) as cited by Greer and Shannon (2005). This buttresses the fact that infants below four months of age are most susceptible to methemoglobinemia.

Nitrates and their effects: Nitrates and nitrites are said to be very hazardous and there are legal limits to their concentration in food and drinking water (Katan, 2009). Agricultural activities are often the main culprits for the contamination of foods and surface water. Fertilizers generally accumulate in vegetables, fruits and possibly 
seep down into water bodies. This makes it difficult to keep waters in farming communities below the legal limits. It is however worth noting that nitrates are often natural components of some foods but the worrying fact is the concentration or its levels in the said foods. Nitrates amounts exceeding legal limits in drinking water and foods could result in detrimental effects such as cancer, methemoglobinemia, birth defects and disruption of thyroid functions.

Methemoglobinemia: Is a blood disorder in infants in which the affected individual suffers from oxygen deprivation. Nitrates are a major cause of methemoglobinemia in infants and this has been of great concern for regulators around the world. Symptoms of methemoglobinemia include: bluish coloring of the skin, headache, fatigue, shortness of breath, convulsion and lack of energy. Complications associated with methemoglobinemia include shock, seizures and death (Boadu, 2008; EWG, 2012).

Cancer: Cancer could result from the ingestion of nitrates. This is basically as a result of series of chemical reactions: ingested nitrates are converted to nitrites and these nitrites react with both synthetic and natural organic compounds to produce N-Nitroso compounds in the human stomach.

Many of these N-Nitroso compounds are said to be carcinogenic in humans (IARC, 1978; NAS, 1977) as cited by EWG (2012). Many scientists are also of the view that high nitrate levels in drinking water may increase cancer risks (Mirvish, 1983; Mirvish, 1991).

Alteration of thyroid function: According Van Maanen et al. (1994) as cited by EWG (2012), individual's drinking water with a high nitrate content exhibited a dose related increase in hypertrophy, a condition marked by enlargement of the thyroid, the gland responsible for many of the body's endocrine and hormonal functions.

Birth defects: Dorsch (1984), Knox (1972) and Super (1981) also have it that, there is a possible link between exposure to nitrite, nitrate and N-Nitroso compounds and birth defects.

The controversy of Nitrates to human health: While a lot from the scientific world believe in the adverse effects of nitrates, many a scientist doubts the adverse effects of nitrates. Butler (2008) and Powlson (2008) as cited by Katan (2009) are in the school of thought that doubts the adverse effects of nitrates since these evidences are said to be inconsistent. They further pointed out that nitrates may actually be beneficial. Hord et al. (2009) buttresses the above by pointing it out that nitrates and nitrites should be considered as nutrients. Larsen et al.
(2006) also contributes to the argument by indicating that nitrates reduce blood pressure. Katan (2009) concludes on this point by saying nitrates reduces cardiovascular diseases risk but was quick to point out that evidence is scanty. I am of the view that prevention as they say is better than cure. Safety limits of nitrates are being contested by different schools of thoughts. A possible solution could therefore include reducing nitrates intake as low as possible bearing in mind that the legal limits are forbidden zones.

Assumptions: The results of the Ghana Demographic and Health Survey results on prelacteal feeding as cited in this work are assumed to be the same as of the time of water sample collection and analysis.

\section{RESULTS}

From chart 1, sixteen water sources (Representing 57\%) had their nitrate concentrations being within the World Health Organization recommendation of nitrate concentration in drinking water not exceeding $10 \mathrm{mg} / \mathrm{L}$. Twelve out of the twenty eight water sources (representing 43\%) had their nitrate concentration above the $\mathrm{WHO}$ recommendation:

C Risk of being expose to contaminated water = 43/100

C Risk of being expose to prelacteal feed $=18 / 100$ Risk of being exposed to methemoglobinemia $=$ $18 / 100 * 43 / 100=0.08$

C (Meaning about one out of every twelve children stands the risk of being exposed to methemoglobinemia when using unregulated water sources)

NB: Contaminated water implies water with nitrate concentration above $10 \mathrm{mg} / \mathrm{L}$

From chart 2, three out of the nine sampled boreholes (representing 33\%) had their nitrate concentration exceeding the $\mathrm{WHO}$ recommendation while six out of the nine (representing 67\%) had their nitrate concentration being within recommendation:

C Risk of being expose to contaminated water when using borehole water $=33 / 100=0.33$

C Risk of being of being expose to prelacteal feed $=$ $18 / 100=0.18$

C Risk of being exposed to methemoglobinemia = $18 / 100 * 33 / 100=0.06$

$C$ (Meaning one out of every seventeen children stands the risk of being exposed to methemoglobinemia when using borehole water )

NB: Contaminated water implies water with nitrate concentration above $10 \mathrm{mg} / \mathrm{L}$ 
Pak. J. Nutr., 11 (10): 900-905, 2012

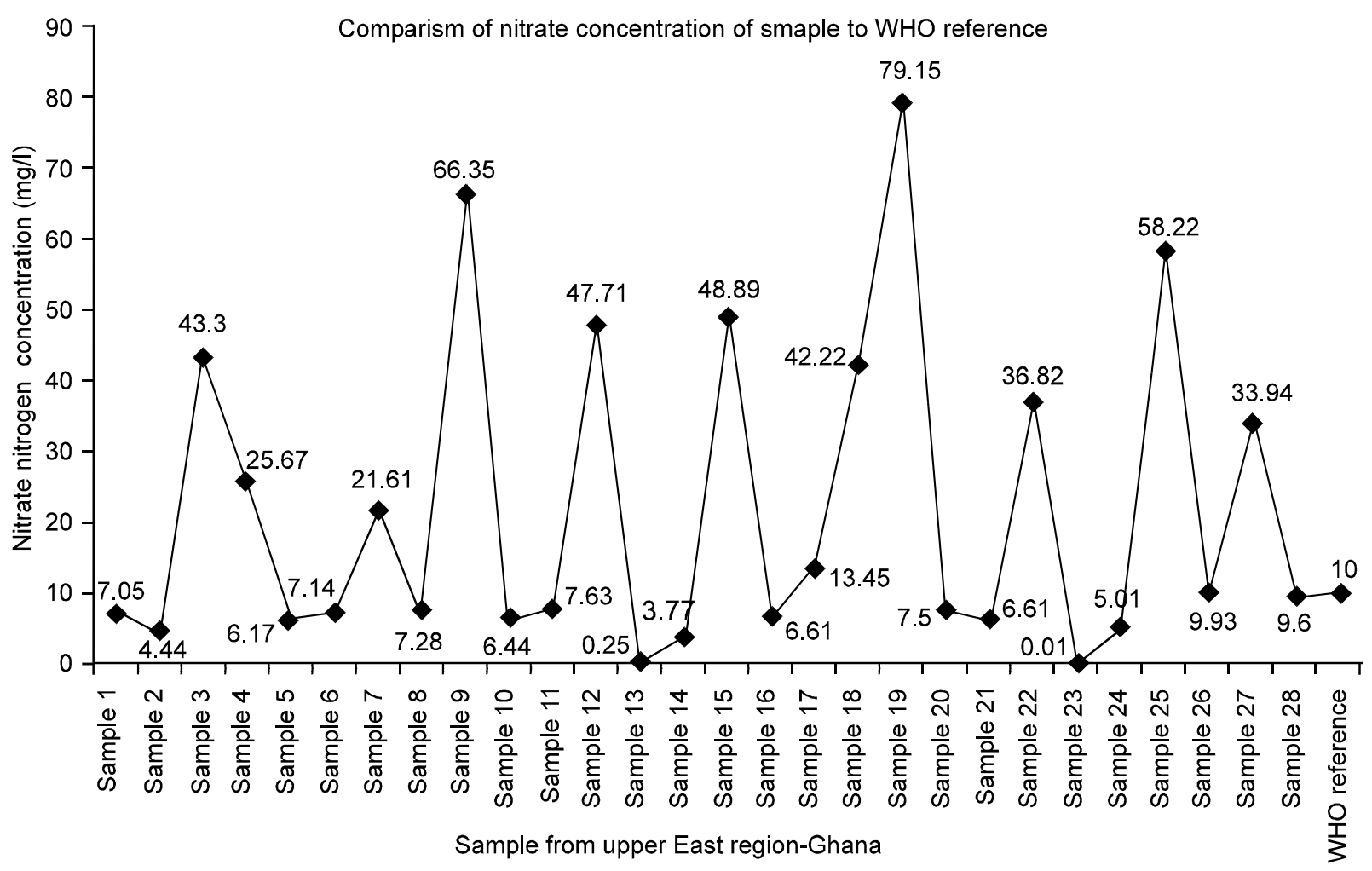

Chart 1: Comparison of nitrate concentration of unregulated drinking water sources to WHO reference, Source: Researcher's Laboratory analysis, 2012

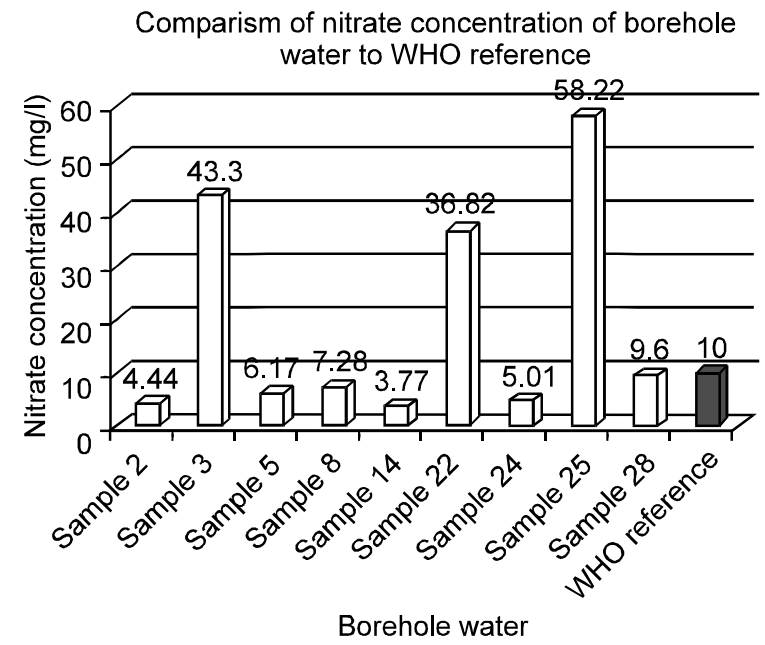

Chart 2: Comparison of nitrate concentration of borehole water to WHO reference, Source: Researcher's Laboratory analysis, 2012

In chart 3, nine out of the nineteen sampled wells (representing 47\%) had their nitrate concentration exceeding the WHO recommendation while ten out of the nineteen (representing 53\%) had their nitrate concentration being within recommendation.

C Risk of being expose to contaminated water when using well water $=47 / 100=0.47$
C Risk of being expose to prelacteal feed $=18 / 100=$ 0.18

C Risk of being exposed to methemoglobinemia $=$ $18 / 100 * 47 / 100=0.08$

C (Meaning one out of every twelve children stands the risk of being exposed to methemoglobinemia when using well water)

NB: Contaminated water implies water with nitrate concentration above $10 \mathrm{mg} / \mathrm{L}$

\section{DISCUSSION}

Nitrate Concentration of unregulated water sources and risk of exposure to methemoglobinemia: Among unregulated water sources, $43 \%$ of them had nitrate levels above accepted limits indicating that nearly three (3) out of seven (7) unregulated water sources exposes the consumers to high nitrate concentration (beyond 10 $\mathrm{mg} / \mathrm{L}$ ) which is highly unacceptable. The sample with the highest nitrate concentration had its value being nearly seven times the recommended upper limit of $10 \mathrm{mg} / \mathrm{L}$. The lowest value was found to be $<0.01 \mathrm{mg} / \mathrm{L}$.

Regarding samples having nitrate concentrations within recommended values, $57 \%$ of them were considered safe for consumption. Implying that nearly four (4) out of seven (7) unregulated water sources could be said to be safe for consumption. The margin between consuming safe and unsafe water from unregulated water sources 
Pak. J. Nutr., 11 (10): 900-905, 2012

Comperiasm of nitrate concentration of well water to WHO reference

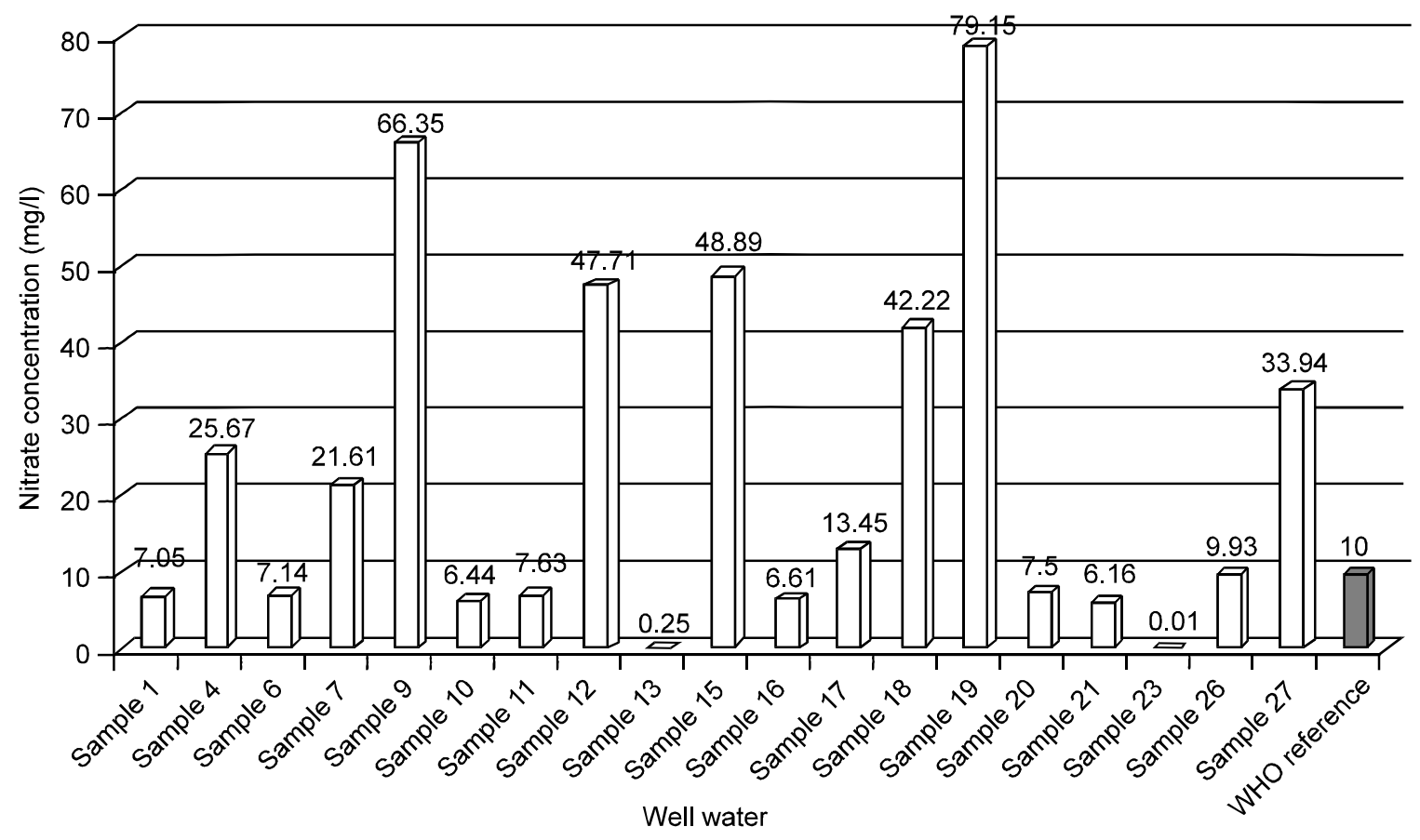

Chart 3: Comparison of nitrate concentration of well water to WHO reference, Source: Researcher's Laboratory analysis, 2012

in the region is very slim. The need for pragmatic measures in ensuring supply of safe water in the Upper East Region cannot therefore be over emphasized.

It is also glaring from the results (chart 1 ) that the risk of being exposed to methemoglobinemia is 0.08 , meaning about one out of every twelve children stands the risk of being exposed to methemoglobinemia when using unregulated water sources. The over all contamination might be linked to soil contamination due to environmental and / or agricultural nitrates in the region. Well water and risk of exposure to methemoglobinemia: From chart $3,47 \%$ of the wells had nitrate levels above accepted limits indicating that nearly seven out of fifteen wells expose consumers to high nitrate concentration. From chart 1 and 3 , it can be seen that the larger values of nitrate concentration $(79.15 \mathrm{mg} / \mathrm{L}, \quad 66.36 \mathrm{mg} / \mathrm{L}$, $48.69 \mathrm{mg} / \mathrm{L}$ etc) are attributed to well water. This trend could be as a result of most of the wells not being covered therefore environmental and/ or agricultural nitrates could easily find their way into them.

The risk of being exposed to methemoglobinemia is 0.08 which is the same as the combined risk for all unregulated water sources. It can therefore be said that well water accounts largely for the risk of exposure to methemoglobinemia in the Upper East Region of Ghana.

Well water samples had the highest $(79.15 \mathrm{mg} / \mathrm{L})$ and the lowest $(<0.01 \mathrm{mg} / \mathrm{L})$ nitrate concentrations. This implies that all things being equal, wells could provide safe and unsafe water sources depending on their nature. Most of the low values came from wells that had covers, though some are from open wells too.

Borehole water and risk of exposure to methemoglobinemia: Chart 2 indicates that $33 \%$ of boreholes (one out of three boreholes) had nitrate levels above accepted limits while $67 \%$ of boreholes (two out of three boreholes) had nitrate levels within accepted limits. The risk of being exposed to methemoglobinemia is 0.06 which is lower than that of wells and unregulated water sources in general. The lower risk of exposure to methemoglobinemia in boreholes as compared to wells could be due to boreholes being covered and sunk deeper than most wells.

Conclusion: Based on the findings of the research and the discussion being made, the following conclusion could be drawn:

C Nearly three out of seven unregulated water sources exposes the consumers to high nitrate concentration (beyond $10 \mathrm{mg} / \mathrm{L}$ )

C Nearly four out of seven unregulated water sources could be said to be safe for consumption

C The margin between consuming safe and unsafe water from unregulated water sources in the region was observed to be very slim

C One out of every twelve children stands the risk of being exposed to methemoglobinemia when using unregulated water sources 
Pak. J. Nutr., 11 (10): 900-905, 2012

C Well water accounts largely for the risk of exposure to methemoglobinemia in the region

$C$ The risk of exposure is higher in wells than in boreholes which is attributed to boreholes being covered and sunk deeper than most wells

C Agricultural activities could be the main culprits for the high contamination of water (especially well water in the region)

Recommendations: The following recommendations have been made based on the findings and conclusions of the study:

C Multi sectorial approach to civic education on the importance of environmental / ground water protection should be employed by all stake holders at regional, district and community levels

C The Ghana water company, the district assemblies and nongovernmental organizations should take keen interest in ensuring wells have covers and are sunk deep enough

C There should be an occasional monitoring of these water sources to check for nitrate amounts

C Further research should be conducted on the nitrate amounts in prelacteal feeds in the region to give a complete picture of the risk associated to being on prelacteal feeding

Further research could be conducted on nitrate concentration in the various seasons (dry and wet season) in the region to ascertain the amounts in the various seasons and to determine which season poses the greatest risk.

\section{ACKNOWLEDGEMENT}

I am grateful to the Council for Scientific and Industrial Research, Water Research Institute, Water Quality Laboratory in Tamale for their support in the analysis of nitrate contents in sampled water.

\section{REFERENCES}

Ahmed, F.U., M.E. Rahman and M.S. Alam, 1996. Prelacteal feeding: influencing factors and relation to establishment of lactation. Bangladesh Med. Res. Counc Bull., 2: 60-64.

Boadu, F.K., F. Owusu-Nimo and A. Menyeh, 2008. Nitrate Contamination in Groundwater at Farmlands in Nsawam, Ghana: The Role of Fractures from Azimuthal Resistivity Surveys. J. Environ. Eng. Geophys, 13: 27-37.

Butler, A.R. and M. Feelisch, 2008. Therapeutic uses of inorganic nitrite and nitrate: from the past to the future. Circulation, 117: 2151-2159.

Dorsch et al., 1984. Congenital malformations and maternal drinking water supply in rural South Australia: A case control study. Am. J. Epidemiol., 119: 473-486.

Environmental Working Group, 2012. Health Effects of Nitrate Exposure. Available at: http:// www.ewg. org/node/7712, accessed on 12/6/2012.
Ghana Demographic and Health Survey - GDHS, 2008. Ghana Statistical Service, Ghana Health Service, Accra, Ghana.

Greer, F.R. and M. Shannon, 2005. Infant Methemoglobinemia: The Role of Dietary Nitrate in Food and Water. Pediatrics, 116: 784.

Hord, N.G., Y. Tang and N.S. Bryan, 2009. Food sources of nitrates and nitrites: the physiologic context for potential health benefits. Am. J. Clin. Nutr., 90: 1-10.

IARC, 1978. IARC Monographs on the Evaluation of Carcinogenic Risks of Chemicals to Man. Volume 17: Some N-Nitroso Compounds. W.H. O.

Kamphake, L.J., S.A. Hannah and J.M. Cohen, 1967 Automated analysis for nitrate by hydrazine reduction. Water Res., 1: 205-216.

Katan, M.B., 2009. Nitrate in foods: harmful or healthy? Am. J. Clin. Nutr., 90: 11-12.

Knox, E.G., 1972. Anencephalus and dietary intakes. Br. J. Preventive Soc. Med., 26: 219-223.

Larsen, F.J., B. Ekblom, K. Sahlin, J.O. Lundberg and E. Weitzberg, 2006. Effects of dietary nitrate on blood pressure in healthy volunteers. N. Engl. J. Med., 355: 2792-2793.

McKnight, G.M., C.W. Duncan, C. Leifert and M.H. Golden, 1999. Dietary Nitrate in man: Friend or Foe? Br. J. Nutr., 81: 349-358.

Mirvish, S.S., 1983. The etiology of gastric cancer: Intragastric nitrosamide formation and other theories. J. Nat. Cancer Institute, 71: 631-647.

Mirvish, S.S. ,1991. The significance for human health of nitrate, nitrite and n-nitroso compounds in Nitrate Contamination: Exposure, Consequence and Control. NATO ASI Series, Vol. G30. Bogardi et al., eds. Springer Verlag. Berlin.

Mullin, J.B. and J.P. Riley, 1955. The spectrophotometer determination of nitrates in natural waters, with particular reference to sea water. Anal. Chim. Acta., 12: 464-480.

National Academy of Sciences-NAS, 1977. Safe Drinking Water Committee. Drinking Water and Health. Washington, D.C.

Phillips W.E., 1971. Naturally occurring nitrate and nitrite in foods in relations to infant methaemoglobinaemia. Food Cosmet Toxicol., 9: 219-228.

Powlson, D.S., T.M. Addiscott and N. Benjamin et al., 2008. When does nitrate become a risk for humans. J. Environs. Qual., 37: 291-295.

Smith, R.P., 1991. Toxic responses of the blood. In Amdur M.O., Doull J, Klaassen CD eds. Casarett and Doull's Toxicology: the basic science of poison. $4^{\text {th }}$ ed. New York NY: Pergamon press, 1991, 257-281.

Super, M. et al., 1981. An epidemiological study of wellwater nitrates in a group of south west African/Namibian infants. Water Research. 15, 12651270 Terry, et al. 1995. Commercial Fertilizers 1995. The Association of American Plant Food Control Officials/The Fertilizer Institute. Washington, DC

Van Maanen et al., 1994. Consumption of drinking water with high nitrate levels causes hypertrophy of the thyroid. Toxicol. Lett., 72: 365-374. 